\title{
Quantitative 3D Telomeric Imaging of Buccal Cells Reveals Alzheimer's Disease-Specific Signatures
}

\author{
Angeles Garcia $^{\mathrm{b}}$, Shubha Mathur ${ }^{\mathrm{a}}$, Maria Carmela Kalaw ${ }^{\mathrm{a}}$, Elizabeth McAvoy ${ }^{\mathrm{b}}$, James Anderson ${ }^{\mathrm{b}}$, \\ Angela Luedke ${ }^{\mathrm{b}}$, Justine Itorralba ${ }^{\mathrm{b}}$ and Sabine $\mathrm{Mai}^{\mathrm{a}, *}$ \\ a Manitoba Institute of Cell Biology, The University of Manitoba, CancerCare Manitoba, Winnipeg, MB, Canada \\ ${ }^{\mathrm{b}}$ Department of Medicine (Geriatrics) and Neuroscience Centre, Queen's University, Kingston, ON, Canada
}

Accepted 26 February 2017

\begin{abstract}
This study validates and expands on our previous work that assessed three-dimensional (3D) nuclear telomere profiling in buccal cells of Alzheimer's disease (AD) patients and non-AD controls (Mathur et al., J Alzheimers Dis 39, $35-48,2014)$. While the previous study used age- and gender-matched caregiver controls, the current study consented a new cohort of 44 age- and gender-matched healthy non-caregiver controls and $44 \mathrm{AD}$ study participants. 3D telomeric profiles of buccal cells of $\mathrm{AD}$ patients and their non-AD controls were examined with participant information blinded to the analysis. In agreement with our previous study, we demonstrate that 3D telomeric profiles allow for the distinction between $\mathrm{AD}$ and non-AD individuals. This validation cohort provides an indication that the total number of 3D telomeric signals and their telomere lengths may be a suitable biomarker to differentiate between $\mathrm{AD}$ and non-AD and between mild, moderate, and severe AD. Further studies with larger sample sizes are required to move this technology further toward the clinic.
\end{abstract}

Keywords: Alzheimer's disease, buccal cells, telomeres

\section{INTRODUCTION}

Alzheimer's disease (AD) is the most common form of dementia affecting approximately five million Americans age 65 and older, as well as an estimated 200,000 Americans under the age of 65 who are afflicted with early-onset $\mathrm{AD}[1,2] . \mathrm{AD}$ is clinically defined as a progressive neurodegenerative disorder that involves cognitive impairment, memory loss, visual-spatial retrogression, and language impairment [3].

Current guidelines set by the Alzheimer's Association and the National Institute of Neurological

\footnotetext{
${ }^{*}$ Correspondence to: Sabine Mai, Manitoba Institute of Cell Biology, The University of Manitoba, CancerCare Manitoba, 675 McDermot Ave, Winnipeg, MB, R3E 0V9, Canada. Tel.: +1 204787 2135; FAX: +1 204787 2190; E-mail: sabine.mai@ umanitoba.ca.
}

Disorders and Stroke identify three stages of AD: preclinical $\mathrm{AD}$, mild cognitive impairment $(\mathrm{MCI})$ due to $\mathrm{AD}$, and dementia due to $\mathrm{AD}$ [4-6]. Every year, approximately $15 \%$ of MCI patients progress to dementia $[1,7,8]$. The final stage, dementia due to $\mathrm{AD}$, can be described as a state that affects memory, thinking, and behavior, thus impairing everyday living of a patient, in addition to significant changes in the brain, cerebrospinal fluid, and blood [9]. Dementia due to $\mathrm{AD}$ is the most common and most identifiable stage of this condition [9]. In this study, we categorized patients into three stages of mild, moderate, and severe AD based on the patient's cognitive scores on MMSE and MoCA examinations [10-12].

Currently, $\mathrm{AD}$ is only confirmed postmortem through pathological studies of the brain and consequently, it is the fifth leading cause of death for people age 65 and older $[1,13]$. Although AD has 
been associated with pathologies such as tau protein hyperphosphorylation and amyloid- $\beta$ (A $\beta$ ) plaque formation, measuring levels of these proteins in the cerebrospinal fluid and blood are not highly specific, and can be invasive [1,9]. Thus, there is a need for a non-invasive biomarker with high sensitivity/specificity that can diagnose $\mathrm{AD}$ and indicate disease progression. In addition to tau and $A \beta$ pathology, AD has also been correlated with markers of genomic instability such as changes in nuclear telomere length [14-18]. A recent meta-study confirmed telomere shortening in $\mathrm{AD}$ [19].

Telomeres are highly repetitive (TTAGGG) $)_{n}$ hexanucleotide sequences situated at the terminal ends of mammalian chromosomes [20-22]. Together with a protein complex termed shelterin, they protect the ends of chromosomes from deterioration and prevent end-to-end fusions with neighboring chromosomes [23]. Telomeres play a vital role in genomic stability and cell senescence, thus making them an important structure in diseases related to genomic instability and aging, including AD [14, 24-27]. Telomeres of normal cells shorten with each cell division until a final critical length is reached; this final critical length is known as the Hayflick limit [28]. At this point of their cell division cycles, normal cells enter a state of senescence, which is considered a tumor preventative state [29]. During senescence, telomeres form aggregates as reported in culture for mesenchymal stem cells [30]. Telomeres were implicated in the agerelated deterioration of hematopoietic stem cells [31]. In line with these observations, oncogene-induced escape from senescence was shown to be associated with derepressed hTERT promoter activity [32]. Changes in telomere biology were recently proposed as possible markers for aging [33], and a recent metaanalysis confirmed the loss of telomere sequences as a feature associated with AD [19]. Thus, telomeres may serve as a biomarker for disease including as aging [34] and cancer [35].
The primary objective of this study was to validate the data on changes in the 3D organization of telomeres in $\mathrm{AD}$ as reported in a previous $\mathrm{AD} /$ non- $\mathrm{AD}$ cohort [28]. In this cohort, we described a noninvasive method to examine and define alterations in $\mathrm{AD}$ and during $\mathrm{AD}$ progression using quantitative $3 \mathrm{D}$ nuclear telomere imaging of buccal cells (BCs). As a follow-up to our initial cohort of 82 subjects with age- and gender-matched caregiver controls (41 AD and 41 non-AD) [36], the current study reports on a second independent patient cohort in which we investigated the 3D nuclear telomeric profiles from $\mathrm{BCs}$ of 88 study participants using age- and gender-matched non-caregiver controls (44 AD and 44 non-AD). This is in contrast to the previous study that was based on caregiver controls [28]. Our data indicate that 3D telomere lengths and telomere numbers are sufficient to distinguish between $\mathrm{AD}$ and non- $\mathrm{AD}$ independent of the control group (caregivers or non-caregivers) and between mild, moderate and severe AD.

\section{MATERIALS AND METHODS}

\section{Study population}

The patients recruited for the study were from Queen's University Memory Clinics and were diagnosed according to the National Institute of Neurological and Communicative Disorders and Stroke, and the Alzheimer's Disease and Related Disorders Association (NINCDS-ADRDA) criteria [3-5]. In total, our study followed $44 \mathrm{AD}$ patients who were age- and sex-matched to 44 normal study participants (Table 1). All AD patients were on standard $\mathrm{AD}$ treatment with cholinesterase inhibitors.

The stratification of AD patients as mild, moderate, or advanced $\mathrm{AD}$ was based on their regular clinic appointments and their respective Montreal Cognitive Assessment (MoCA) score and the Mini-Mental

Table 1

Patient demographics

\begin{tabular}{lcccc}
\hline Population & $\begin{array}{c}\text { Test Score Ranges } \\
(\text { MoCA/30:MMSE/30) }\end{array}$ & $\begin{array}{c}\text { Number of } \\
\text { Subjects }\end{array}$ & $\begin{array}{c}\text { Mean Age } \\
\text { (y } \pm \text { S.D) }\end{array}$ & $\begin{array}{c}\text { Gender } \\
(\text { Male/Female) }\end{array}$ \\
\hline Mild AD & $>18: \geq 22$ & 24 & $76.8 \pm 9.3$ & $6 / 17$ \\
Controls, Mild AD & N/A & 24 & $75.2 \pm 9.9$ & $6 / 17$ \\
Moderate AD & $\leq 18: 21-16$ & 15 & $75.8 \pm 9.3$ & $7 / 8$ \\
Controls, Moderate AD & N/A & 15 & $74.5 \pm 7.6$ & $7 / 8$ \\
Severe AD & $--:<16$ & 5 & $85.2 \pm 1.6$ & $2 / 3$ \\
Controls, Severe AD & N/A & 5 & $83.2 \pm 2.5$ & $2 / 3$ \\
\hline
\end{tabular}

AD, Alzheimer's disease; MoCA, Montreal Cognitive Assessment; MMSE, Mini-Mental State Examination. All patients were on treatment with cholinesterase inhibitors. 
State Examination (MMSE) evaluations [10-12]. Patients with a MoCA score of $>18 / 30$ and/or MMSE score of $\geq 22 / 30$ were considered to have mild AD. Patients with a MoCA score of $\leq 18 / 30$ and/or MMSE score between $21 / 30$ and $16 / 30$ were considered to be in the moderate stage of AD. Finally, patients with an MMSE score lower than $16 / 30$ were considered to have severe AD. In this study that was performed in a blinded manner, no other classification of $\mathrm{AD}$ was done, and no information on disease duration or comorbidities was available.

\section{Collection of buccal cells and sample preparation}

The collection of patient samples was done as previously described [36]. Using Epicentre Catch-A11 sample collection swabs, buccal cells were collected by the Queen's University Memory Clinics' personnel in duplicates from each participant's cheek and smeared onto a marked square of microscope VWR pre-cleaned frosted slides. The slides were frozen at $-20^{\circ} \mathrm{C}$ and shipped to the University of Manitoba in dry ice. The Manitoba laboratory personnel were blinded to sample diagnoses, which were revealed upon completion of sample imaging and analysis.

\section{Three-dimensional quantitative fluorescent in} situ hybridization of telomeres ( $3 D Q-F I S H)$

3D Q-FISH was carried out as follows: Slides were fixed using fresh $3.7 \%$ formaldehyde $/ 1 \times$ phosphate buffered saline buffer (PBS) (formaldehyde, Sigma-Aldrich, St. Louis, MO; Sodium chloride $(\mathrm{NaCl})$, EM Science, Darmstadt, Germany; Potassium chloride $(\mathrm{KCl})$, Fisher Scientific, Fair Lawn, $\mathrm{NJ}$; Sodium phosphate $\left(\mathrm{Na}_{2} \mathrm{HPO}_{4}\right)$, Fisher Scientific; Potassium phosphate $\left(\mathrm{KH}_{2} \mathrm{PO}_{4}\right)$, Sigma-Aldrich) for 20 min and washed in $1 \times$ PBS $(\mathrm{NaCl}$, EM Science; $\mathrm{KCl}$, Fisher Scientific; $\mathrm{Na}_{2} \mathrm{HPO}_{4}$, Fisher Scientific; $\mathrm{KH}_{2} \mathrm{PO}_{4}$, Sigma-Aldrich) three times for 5 min each cycle. Slides were then incubated in $0.5 \%$ Triton X-100 (Sigma-Aldrich) for $10 \mathrm{~min}$, followed by incubation in 20\% glycerol (Sigma-Aldrich) for $60 \mathrm{~min}$. Four repeated cycles of a glycerol/liquid nitrogen freeze-thaw treatment were performed. Afterwards, the slides underwent three $1 \times$ PBS washes for $5 \mathrm{~min}$ each cycle. The slides were then incubated in $0.1 \mathrm{M}$ hydrochloric acid ( $\mathrm{HCl}$ ) (Sigma-Aldrich) for $5 \mathrm{~min}$ and $15 \mathrm{~s}$ followed by two washes of $5 \mathrm{~min}$ in $1 \times$ PBS. After equilibration at room temperature for $1-2 \mathrm{~h}$ in $70 \%$ Formamide $/ 2 \times$ saline-sodium citrate buffer (SSC) (Formamide, Sigma-Aldrich; NaCl, EM Science; Sodium citrate (NaH2C6H5O7), Fisher Scientific) at $\mathrm{pH} 7.0$, slides were washed twice for $5 \mathrm{~min}$ in $1 \times$ PBS, and thereafter hybridized with four $\mu l$ of telomere peptide nucleic acid (PNA) probe (DAKO, Glostrup, Denmark) using a Hybrite ${ }^{\mathrm{TM}}$ (Vysis, Abbott Diagnostics, Des Plains, IL). The samples underwent denaturation for $3 \mathrm{~min}$ at $80^{\circ} \mathrm{C}$, followed by probe annealing to the template for $2 \mathrm{~h}$ at $30^{\circ} \mathrm{C}$. Slides then underwent a series of washes in $70 \%$ Formamide/10 mM Tris at pH 7.4 (Formamide, Sigma-Aldrich; Tris, Sigma-Aldrich) three times for $15 \mathrm{~min}$ each cycle, $1 \times$ PBS one cycle for $1 \mathrm{~min}$, $0.1 \times \mathrm{SSC}$ at $55^{\circ} \mathrm{C}$ one cycle for $5 \mathrm{~min}$, and $2 \times$ SSC/0.05\% Tween-20 (Tween-20, Sigma-Aldrich) three times for $5 \mathrm{~min}$ each cycle. Afterwards, cells were counterstained using $0.1 \mu \mathrm{g} / \mathrm{ml}, 4$ ' 6 -diamidino2-phenylindole (DAPI) (Sigma-Aldrich). Slides were rinsed with deionized distilled water (DDW) to remove excess DAPI and incubated in DDW for 2 min. Lastly, slides were mounted with Vectashield (Vector Laboratories, Burlington, Ontario, Canada).

\section{TeloView: Semi-automated image acquisition and analysis}

3D fluorescence microscopy was performed using a Zeiss AxioImager Z1 microscope (Carl Zeiss, Toronto, Ontario), equipped with an AxioCam HRm camera and $63 \times / 1.4$ oil Plan Apochromat objective as described previously [36]. The data acquisition was carried out using the AXIOVISION 4.8 software (Carl Zeiss). For 3D imaging, 80 image z-stacks were taken with a sampling distance of $200 \mathrm{~nm}$ along the $z$ axis and $102 \mathrm{~nm}$ in the $x, y$ directions. Cyanine $3(\mathrm{Cy} 3)$ and DAPI filters were used in multichannel mode in order to visualize the telomere PNA probe signals and nuclear DNA staining, respectively. To standardize fluorescent intensity between samples, the same exposure time of $800 \mathrm{~ms}$ was used for $\mathrm{Cy} 3$ imaging of telomeres in all interphase nuclei. Earlier work has shown that fluorescent intensity is proportional to size [37].

The recorded images were deconvolved using a constrained iterative algorithm [38], converted into TIFF files and analyzed using the TeloView ${ }^{\mathrm{TM}}$ software [27] (3D Signatures Inc., Winnipeg, MB, Canada). TeloView ${ }^{\mathrm{TM}}$ loads the 3D images and displays a maximum projection along the three axes, $x, y$, and $z$. Using TeloView ${ }^{\mathrm{TM}}$, we measured the following parameters for 30 interphase buccal cell nuclei per patient and determined telomeric signal 
intensity (telomere length), the number of telomeric signals, the number of telomere aggregates, and $a / c$ ratio. The latter pertains to the $3 \mathrm{D}$ spatial position of telomeres during the cell cycle and was described in detail by Vermolen et al. [27]: Telomeres in nuclei are positioned within a spheroid structure. A spheroid has the two main axes, $a$ and $b$, which are equal in length, and a third axis $c$ that has a different length; if $\mathrm{a}<\mathrm{c}$, we have a prolate spheroid; and if $\mathrm{a}>\mathrm{c}$, we have an oblate spheroid. We can therefore define a telomere ratio parameter, $\rho \mathrm{T}$, which gives us a measurement of the disk-like nature of this organization. If $\rho \mathrm{T} \sim 1$, then the telomeres are distributed in a spherical way within the cell. However, if $\rho \mathrm{T}>1$, then the telomeric territory is more disk-like. This measurement has allowed us to classify the 3D telomere positions during the cell cycle. In brief, large $a / c$ ratios represent cells in $\mathrm{G} 2$, while small $a / c$ ratios represent cells in G0/G1 and S (for additional details, see [27].

Using the different telomeric aspects described above, TeloView ${ }^{\mathrm{TM}}$ generated specific 3D telomere profiles for each buccal sample examined.

\section{Statistical analysis}

For each 3D parameter, by-pair analysis comparing each $\mathrm{AD}$ patient to his/her matched control was conducted via chi-square analysis or Wilcoxon rank sum tests. As a group of similar AD severity, the comparisons were done using randomized blocks analysis of variance and Mantel Haenszel stratified analysis, followed by the Breslow-Day test for homogeneity across pairs as well as a log-linear analysis. To compare each AD severity to one another, we tested for severity effect with nested randomized block ANOVAs. Contingency analysis and MantelHaenszel stratified analysis were used to compare distributions of telomere signal fluorescent intensity (telomere length) categorized by quartiles. Significance level was set at $p<0.05$. We calculated that with 44 matched pairs in a randomized block design we have more than $80 \%$ power to detect effect sizes as large as those observed previously between $\mathrm{AD}$ and controls of moderate and severe groups for both the telomere lengths and telomere signals.

\section{RESULTS}

\section{Semi-automated 3D image acquisition and analysis using TeloView}

3D imaging of buccal cells was performed from $\mathrm{AD}$ and non-AD study participants. Figure 1 shows a representative example of the $2 \mathrm{D}$ and $3 \mathrm{D}$ telomeric imaging that is performed on buccal cells (Materials and Methods). A comparison of all AD groups (mild, moderate, and severe) was published in our previous study [36]. The imaging data were quantified using TeloView ${ }^{\mathrm{TM}}$ (Materials and Methods).

When compared with our previous study [36], all 3D telomere parameters were confirmed as indicated in Table 2. Two exceptions were noted, namely, the $a / c$ ratio and aggregate numbers in severe $\mathrm{AD}$, which showed differences from the earlier study (Table 2,

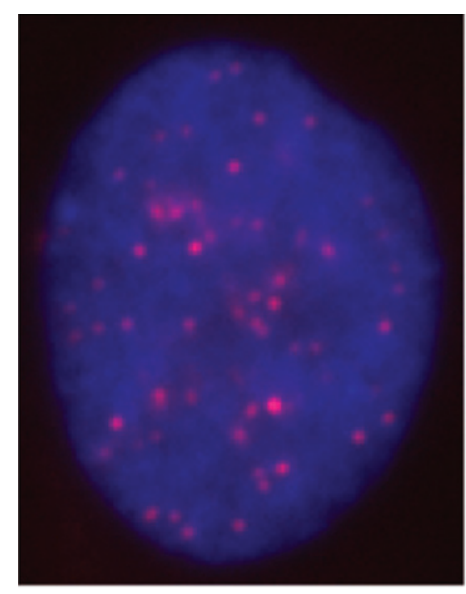

a

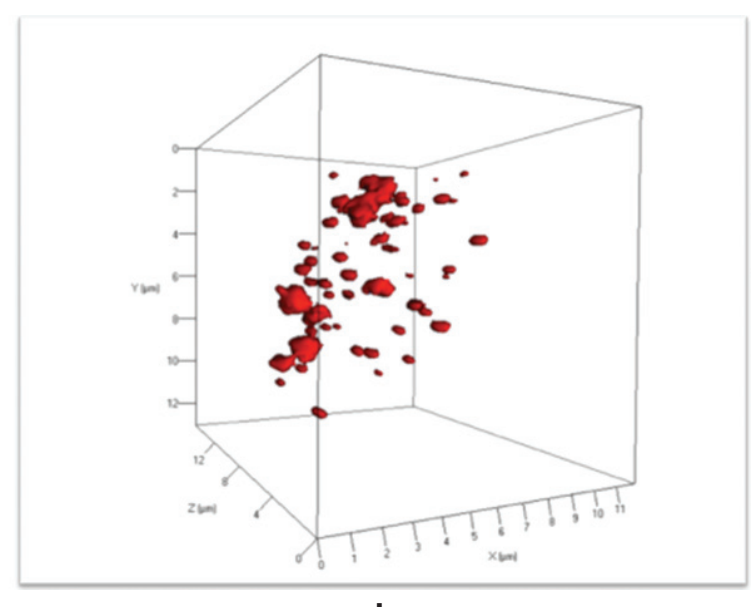

b

Fig. 1. Representative two (2)- and three dimensional (3D) image of a buccal cell nucleus hybridized with a CY3-labled telomere probe (red) (Materials and Methods). (a) 2D image of nucleus hybridized with CY3-labled telomere probe (red). Nucleus (blue). (b) 3D image of the identical nucleus. Telomeres are shown in red. Disease progression and telomere images were illustrated in [36]. 
Table 2

3D telomere parameters of $\mathrm{AD}$ and non-AD study participants

\begin{tabular}{|c|c|c|c|c|c|c|c|}
\hline \multirow[b]{2}{*}{ Participant } & \multirow[b]{2}{*}{ Diagnosis } & \multirow[b]{2}{*}{$\begin{array}{l}\text { Number of } \\
\text { subjects }\end{array}$} & \multicolumn{5}{|c|}{ Nuclear 3D telomere parameters } \\
\hline & & & $\begin{array}{l}\text { Telomere length } \\
>15000 \text { [a.u.] }\end{array}$ & $\begin{array}{l}\text { Number of } \\
\text { telomeres }\end{array}$ & $\begin{array}{c}\text { Nuclear volume } \\
{\left[\mu^{3}\right]}\end{array}$ & $a / c$ ratio & $\begin{array}{c}\text { Telomeric } \\
\text { aggregates }\end{array}$ \\
\hline \multirow[t]{2}{*}{ Mild AD } & Mild AD & 24 & $p>0.0001$ & 0.4487 & 0.1892 & 0.9807 & 0.2532 \\
\hline & Control & 24 & & & & & \\
\hline Moderate & Moderate AD & 15 & $p>0.0001$ & 0.0037 & 0.9863 & 0.1415 & 0.0554 \\
\hline $\mathrm{AD}$ & Control & 15 & & & & & \\
\hline Severe & Severe AD & 5 & $p>0.0001$ & 0.0452 & 0.9987 & $0.0024^{\#}$ & $0.1984^{\#}$ \\
\hline $\mathrm{AD}$ & Control & 5 & & & & & \\
\hline
\end{tabular}

Summary of 3D nuclear telomere parameters according to clinical diagnosis. While the data confirm the study cohort examined by Mathur et al. [36, Table 3], "\#indicates data different from the previous study. For the discussion of these data, see text. [a.u.] - arbitrary units.

$p=0.0024$ and 0.1984 respectively). It is of note that the low number of severe AD participants and non$\mathrm{AD}$ controls in the current cohort (five each) may likely be the cause of this difference (Tables 1 and 2).

We found a significant increase in telomere length attrition and telomere number elevation in buccal cells of AD patients compared to their respective controls and as $\mathrm{AD}$ progressed from mild to moderate to severe (Table 2). The telomere length differences measured between $\mathrm{AD}$ and non-AD and between mild, moderate and severe AD were highly significant (Table 2, $p<0.0001$ ) as non-caregiver controls were participating in the current study. Moreover, the increase in the detected telomere numbers was significant as the disease progressed from mild to moderate to severe $\mathrm{AD}$ ( $p=0.0037$ for the difference between mild and moderate $\mathrm{AD}$, and $p=0.0452$ for the difference between moderate and severe AD).

As reported previously [36], nuclear volumes and $a / c$ ratios remained unchanged $(p>0.05)$, with the exception of the $a / c$ ratio in severe $\mathrm{AD}$ versus controls $(p=0.0024)$ (Table 2). Telomeric aggregates showed a trend to increase in moderate AD compared to mild $\mathrm{AD}$ and their respective controls $(p=0.0554)$ (Table 2).

\section{DISCUSSION}

While many studies have been performed the analysis of telomeres and genomic instability in $\mathrm{AD}$ [14-18], 3D analysis of telomeric architecture and DNA structure have not been conducted before, except as done in our previous study [36]. The current study was conducted under a new experimental design, in which we investigated age- and sex-matched non-caregiver controls and AD participants and the 3D telomeric parameters of buccal cells from both groups. This point is important as caregivers are expected to exhibit telomere shortening as a result of constant and long-lasting daily stress $[39,40]$.

Nuclear volumes were unchanged and so were $a / c$ ratios, except for severe AD. However, the low number of study participants in this group of AD patients may have had an impact on this result. An increase in telomere aggregates was noted in our previous $\mathrm{AD}$ study cohort compared to controls, and as AD progressed. In the current study, moderate AD showed a trend to significance $(p=0.0554)$, while severe AD did not follow this trend.

The current cohort confirmed the previously published data on 3D nuclear telomere profiling of $\mathrm{AD}$ and non-AD [28] showing that 3D nuclear telomere numbers were elevated and telomere lengths decreased. Overall, the difference between telomere lengths in $\mathrm{AD}$ and non- $\mathrm{AD}$ was more significant in the current study cohort than in the Mathur et al. [36] cohort. While the 2014 data showed significance in telomere length decrease, the current data indicate indirectly that the shorter telomeres of caregivers reduced the significance between the groups in the previous cohort. Therefore, the recent data on telomere length decreases show higher significance than those in the previous one [28]. While both studies indicate significant telomere length decreases, the current study shows the highest significance in differences measured between $\mathrm{AD}$ and non-AD and between AD subgroups (mild, moderate, and severe) $(p<0.0001)$. A recent meta-analysis that focused on telomere length alone confirmed our findings of shorter telomeres in $\mathrm{AD}$ as a general feature of AD [19].

Taken together, our data indicate that 3D telomere profiles can differentiate between $\mathrm{AD}$ and non-AD and between $\mathrm{AD}$ severity groups. This finding may be important in determining the onset of $\mathrm{AD}$ as well as its progression and enable future personalized $\mathrm{AD}$ 
patient management. Limitations of this study are the numbers of patients enrolled and the medical classification system used (MoCA and MMSE without additional clinical classification, absence of information on disease duration and comorbidities). Future validation of these findings in larger cohorts and with detailed clinical classification is recommended.

\section{ACKNOWLEDGMENTS}

The authors would like to thank all study participants. We thank 3D Signatures Inc. for the use of TeloView ${ }^{\mathrm{TM}}$. The study was funded by the Cognition Challenge (Johnson \& Johnson Innovation) and supported by the Canadian Consulate in San Francisco. We thank Mary Cheang for statistical analysis and Paul-Émile Crevier, Harpreet Bhullar, and Rosa Seo for technical support.

Authors' disclosures available online (http://j-alz. com/manuscript-disclosures/16-1169r2).

\section{REFERENCES}

[1] Alzheimer's Association (2014) 2014 Alzheimer's Disease Facts and Figures. Alzheimers Dement 10, e47-e92.

[2] Hebert L, Weuve J, Scherr P, Evans D (2013) Alzheimer disease in the United States (2010-2050) estimated using the 2010 Census. Neurology 80, 1778-1783.

[3] McKhann G, Drachman D, Folstein M, Katzman R, Price D, Stadlan EM (1984) Clinical diagnosis of Alzheimer's disease: Report of the NINCDS-ADRDA Work Group under the auspices of Department of Health and Human Services Task Force on Alzheimer's Disease. Neurology 34, 939-944.

[4] Jack CR, Albert MS, Knopman DS, McKhann GM, Sperling RA, Carrillo MC, Thies B, Phelps CH (2011) Introduction to the recommendations from the National Institute on Aging-Alzheimer's Association workgroups on diagnostic guidelines for Alzheimer's Disease. Alzheimers Dement 7, 257-262.

[5] Albert MS, DeKosky ST, Dickson D, Dubois B, Feldman HH, Fox NC, Gamst A, Holtzman DM, Jagust WJ, Petersen RC, Snyder PJ, Carrillo MC, Thies B, Phelps CH (2011) The diagnosis of mild cognitive impairment due to Alzheimer's disease: Recommendations from the National Institute on Aging-Alzheimer's Association workgroups on diagnostic guidelines for Alzheimer's disease. Alzheimers Dement 7, 270-279.

[6] McKhann GM, Knopman DS, Chertkow H, Hyman BT, Jack CR, Kawas CH, Klunk WE, Koroshetz WJ, Manly JJ, Mayeux R, Mohs RC, Morris JC, Rossor MN, Scheltens P, Carrillo MC, Thies B, Weintraub S, Phelps CH (2011) The diagnosis of dementia due to Alzheimer's disease: Recommendations from the National Institute on Aging - Alzheimer's Association workgroups on diagnostic guidelines for Alzheimer's disease. Alzheimers Dement 7, 263-269.

[7] Hanninen T, Hallikainen M, Tuomainen S, Vanhanen M, Soininen H (2002) Prevalence of mild cognitive impairment:
A population-based study in elderly subjects. Acta Neurol Scand 106, 148-154.

[8] Petersen RC, Smith GE, Waring SC, Ivnik RJ, Tangalos EG, Kokmen E (1999) Mild cognitive impairment: Clinical characterization and outcome. Arch Neurol 56, 303-308.

[9] Tan L, Yu J, Liu Q, Tan M, Zhang W, Hu N, Wang Y, Sun L, Jiang T, Tan L (2014) Circulating miR-125b as a biomarker of Alzheimer's disease. J Neurol Sci 336, 52-56.

[10] Nasreddine ZS, Phillips NA, Bedirian V, Charbonneau S, Whitehead V, Collin I, Cummings JL, Chertkow H (1995) The Montreal Cognitive Assessment, MoCA: A brief screening tool for mild cognitive impairment. J Am Geriatr Soc 53, 695-699.

[11] Folstein MF, Folstein SE, McHugh PR (1975) "Mini-mental state". A practical method for grading the cognitive state of patients for the clinician. J Psychiatr Res 12, 189-198.

[12] McDowell I, Kristjansson B, Hill GB, Hebert R (1997) Community screening for dementia: The Mini Mental State Exam (MMSE) and Modified Mini-Mental State Exam (3MS) compared. J Clin Epidemiol 50, 377-383.

[13] Boustani M, Peterson B, Hanson L, Harris R, Lohr K (2003) Screening for dementia in primary care: A summary of the evidence for the U.S. Preventative Services task force. Ann Intern Med 138, 927-937.

[14] Cai Z, Yan L, Ratka A (2013) Telomere shortening and Alzheimer's disease. Neuromol Med 15, 25-48.

[15] Geller LN, Potter H (1999) Chromosome missegregation and trisomy 21 mosaicism in Alzheimer's diseas. Neurobiol Dis 6, 167-179.

[16] Migliore L, Testa A, Scarpato R, Pavese N, Petrozzi L, Bonuccelli U (1997) Spontaneous and induced aneuploidy in peripheral blood lymphocytes of patients with Alzheimer's Disease. Hum Genet 101, 299-305.

[17] Thomas P, Fenech M (2008) Chromosome 17 and 21 aneuploidy in buccal cells is increased with ageing and in Alzheimer's disease. Mutagenesis 23, 57-65.

[18] Panossian LA, Porter VR, Valenzuela HF, Zhu X, Reback E, Masterman D, Cummings JL, Effros RB (2003) Telomere shortening in T cells correlates with Alzheimer's disease status. Neurobiol Aging 24, 77-84.

[19] Forero DA, González-Giraldo Y, López-Quintero C, CastroVega LJ, Barreto GE, Perry G (2016) Meta-analysis of telomere length in Alzheimer's disease. J Gerontol A Biol Sci Med Sci 71, 1069-1073.

[20] Watson JD (1972) Origin of concatemic T7 DNA. Nat New Biol 239, 197-201.

[21] Olovnikov AM (1972) The immune response and the process of marginotomy in lymphoid cells. Vestn Akad Nauk SSSR 27, 85-87.

[22] Kruk PA, Rampino NJ, Bohr VA (1995) DNA damage and repair in telomeres: Relation to aging. Proc Natl Acad Sci U S A 92, 258-262.

[23] de Lange $\mathrm{T}$ (2005) Shelterin: The protein complex that shapes and safeguards human telomeres. Genes Dev 19, 2100-2110.

[24] Thomas P, O'Callaghan NJ, Fenech M (2008) Telomere length in white blood cells, buccal cells and brain tissue and its variation with ageing and Alzheimer's disease. Mech Ageing Dev 129, 183-190.

[25] Gadji M, Adebayo Awe J, Rodrigues P, Kumar R, Houston DS, Klewes L, Dièye TN, Rego EM, Passetto RF, de Oliveira FM, Mai S (2012) Profiling three-dimensional nuclear telomeric architecture of myelodysplastic syndromes and acute myeloid leukemia defines patient subgroups. Clin Cancer Res 18, 3293-3304. 
[26] Knecht H, Kongruttanachok N, Sawan B, Brossard J, Prévost S, Turcotte E, Lichtensztejn Z, Lichtensztejn D, Mai S (2012) Three-dimensional telomere signatures of Hodgkin- and Reed-Sternberg cells at diagnosis identify patients with poor response to conventional chemotherapy. Transl Oncol 5, 269-277.

[27] Vermolen B, Garini Y, Mai S, Mougey V, Fest T, Chuang T, Chuang A, Wark L, Young I (2005) Characterizing the three-dimensional organization of telomeres. Cytometry $A$ 67, 144-150.

[28] Hayflick L (1965) The limited in vitro lifetime of human diploid cell strains. Exp Cell Res 37, 614-636.

[29] Campisi J (2001) Cellular senescence as tumor-suppressor mechanism. Trends Cell Biol 11, 27-31.

[30] Raz V, Vermolen BJ, Garini Y, Onderwater JJ, MommaasKienhuis MA, Koster AJ, Young IT, Tanke H, Dirks RW (2008) The nuclear lamina promotes telomere aggregation and centromere peripheral localization during senescence of human mesenchymal stem cells. J Cell Sci 121(Pt 24), 4018-4028.

[31] Kim MJ, Kim MH, Kim SA, Chang JS (2008) Age-related deterioration of hematopoietic stem cells. Int J Stem Cells 1, 55-63.

[32] Patel PL, Suram A, Mirani N, Bischof O, Herbig U (2016) Derepression of hTERT gene expression promotes escape from oncogene-induced cellular senescence. Proc Natl Acad Sci U S A 113, E5024-E5033.

[33] Ishikawa N, Nakamura K, Izumiyama-Shimomura N, Aida J, Matsuda Y, Arai T, Takubo K (2016) Changes of telomere status with aging: An update. Geriatr Gerontol Int Suppl 1, 30-42.

[34] Seimiya H (2015) Predicting risk at the end of the end: Telomere G-tail as a biomarker. EBioMedicine 2, 804-805.

[35] Mai S (2010) Initiation of telomere-mediated chromosomal rearrangements in cancer. J Cell Biochem 109, 1095-1102.

[36] Mathur S, Glogowska A, McAvoy E, Righolt C, Rutherford J, Willing C, Banik U, Ruthirakuhan M, Mai S, Garcia A (2014) Three-dimensional quantitative imaging of telomeres in buccal cells identifies mild, moderate, and severe Alzheimer's disease patients. J Alzheimers Dis 39, 35-48.

[37] Poon SS, Martens UM, Ward RK, Lansdorp PM (1999) Telomere length measurements using digital fluorescence microscopy. Cytometry 36, 267-278.

[38] Schaefer LH, Schuster D, Herz H (2001) Generalized approach for accelerated maximum likelihood based image restoration applied to three-dimensional fluorescence microscopy. J Microsc 204, 99-107.

[39] Damjanovic AK, Yang Y, Glaser R, Kiecolt-Glaser JK, Nguyen H, Laskowski B, Zou Y, Beversdorf DQ, Weng NP (2007) Accelerated telomere erosion is associated with a declining immune function of caregivers of Alzheimer's disease patients. J Immunol 179, 4249-4254.

[40] O'Donovan A, Tomiyama AJ, Lin J, Puterman E, Adler NE, Kemeny M, Wolkowitz OM, Blackburn EH, Epel ES (2012) Stress appraisals and cellular aging: A key role for anticipatory threat in the relationship between psychological stress and telomere length. Brain Behav Immun 26, 573-579. 